\title{
OBSTACLES TO AND MOTIVATION FOR SUCCESSFUL BREAST-FEEDING
}

\author{
A-M Bergh
}

\begin{abstract}
This study determined obstertit phystother apists perceplions about major obstacles to and methods of motivation for successful

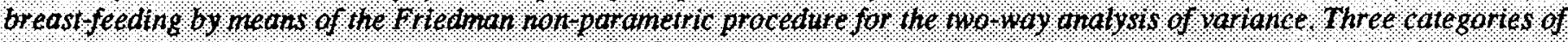
obstacles were identifted. maternat obstactes, health profescionals and society. Maternat obstacles mentioned most Were

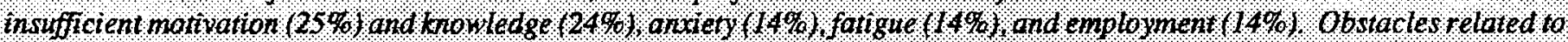
health professionals included tack of support for mothers $(20 \%$, inappropriate lactation management $1.9 \%$ ). lack of knowledge

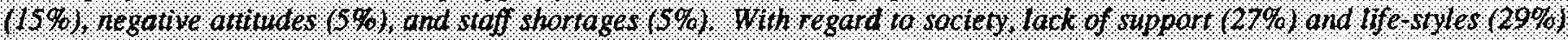
were identified as signficant obstacles. The two nost signifteanth important methods of nottuation were information and education (53\%), and contact with other breastfeeders. $27 \% \%$. 1 i is concluded that breast-feeding education efforts can be improved by identifying obstacles to breast-feeding and methods of motivation and that the Friedman test may be a statistical procedure to consider for derermining priorities.
\end{abstract}

\section{OPSOMMTNG}

Hierdie studie het vertoskundige fisioterapeute se persepsies oor hoofstruikelblokke ten opsigte van en motive-ringsmetodes vin gestaggde borsvoeding met behulp van Friedmion se nie-parametriese prosedwe vil die tweerighinganalise van variansie bepaat.

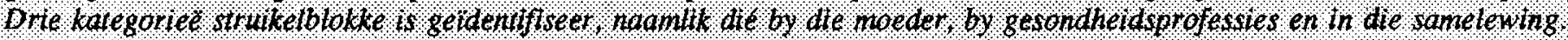

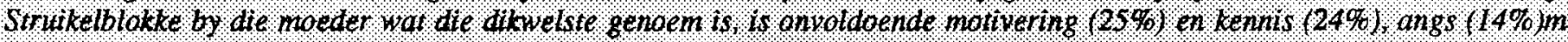

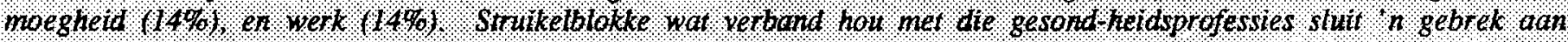
ondersteuning wi noeders (20\%), onbetioorlike hantering vai borsvoeding (19\%), gebrek aan kennis (15\%), negafiewe houdings (5\%), en per soneettelorte (5\%) in. Ten opsigte van die samelewing is gebrek aun ondersteuning (27\%) en lewenstrle (20\%) os betekeniwyolle struikelblokke getdentifweer. Die wee mees betekenisvolle motweringsmetodes was inligting en voorligting (53\%).

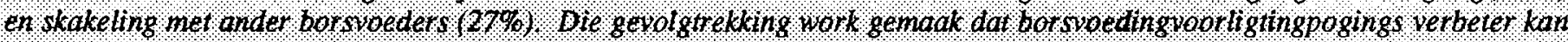

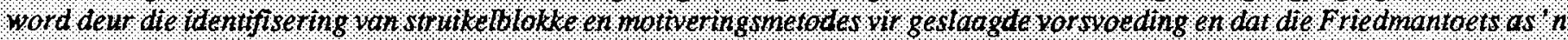
statistiese prosedure oorweeg kan word vir die vasstel van prioriteite.

The practical management of breast-feeding has changed much in Western societies during the past two decades, and the promotion of breast-feeding has been receiving more attention than previously. In many countries, including South Africa, breast-feeding awareness campaigns are organised on a regular basis. Breast-feeding is also part of the GOBI-FFF* principles of the primary health care strategy. In South Africa, there has been an increase in the number of articles on breast-feeding published in professional journals and newsletters. In the more affluent white communities of South Africa, there appears to be an increase in breast-feeding rates (Bergh 1987: 117). Two important ways of maintaining this renewed interest in breast-feeding are through childbirth education and through the improvement of institutional practices harmful to breast-feeding.

Childbirth educators play an important role in motivating mothers-to-be to breast-feed and in providing continued support in the postpartum period. In South Africa, obstetric physiotherapists also act as childbirth educators. Reports on their experiences could

\footnotetext{
* GOBI-FFF is the acronym for growth monitoring, oral rehydration, breast-feeding, immunisation, food supplementation, family spacing, and female education.
}

assist other childbirth educators to motivate and support breast-feeding mothers more effectively.

The aim of this study was to determine

(a) the perceptions of obstetric physiotherapists about major obstacles to successful breast-feeding; and

(b) what types of motivation they considered to be conducive to successful breast-feeding.

\section{SUBJECTS, METHODS AND STATISTICAL ANALYSIS}

Postal questionnaires in English, with an Afrikaans translation on the reverse side, were sent to all 134 members of the Obstetric Association of the South African Society for Physiotherapy in March 1990. A reminder was posted three weeks after the closing date. The total response rate was $44 \%(n=59)$, of which $13,6 \%(n=8)$ were late responses.

Questions pertaining to demographic data were closed-ended. These requested information on the following: whether respondents were currently practising as obstetric physiotherapists (i.e. conducting ante- and postnatal classes); where they had done their basic training and in what year they had completed it; and whether they had received further training in breast-feeding during the previous five years. This information is summarised in Table 1.

Questions on obstacles to successful breast-feeding, and on methods of motivation, were open-ended in order to avoid possible researcher bias in the choice of categories.

The loglinear model applied to contingency tables was used to establish associations between different variables. For the analysis of two by two contingency tables, Fisher's exact test was applied. To identify important significant categories given by respondents in the open-ended questions, the Friedman non-parametric procedure for the two-way analysis of variance was used.

\section{RESULTS}

\section{Obstacles to successful breast-feeding}

The obstacles to successful breast-feeding were divided into three broad categories, viz. maternal obstacles, health professionals and society. Each category was further divided into sub-categories. In order to establish which of these sub-categories respondents considered to be significantly more important than others, the following procedure was followed: Firstly, Friedman's non-parametric 
two-way analysis of variance test was applied at a $5 \%$ level of significance. Secondly, if such differences existed, a multiple comparison technique based on Friedman rank sums (henceforth called the Friedman test) was used to establish the particular differences.

Thirteen maternal obstacles were identified by 43 respondents. Although the Friedman test indicated significant differences, no further divisions into sub-categories could be made, not even at a $20 \%$ significance level. This is probably due to the small sample size, whereas the multiple comparison technique is usually based on an asymptotic result. The maternal obstacles are summarised in Table 2.

Six items were identified by 27 respondents as obstacles relating to health professionals (see Table 3). Eleven respondents $(18,6 \%)$ specifically mentioned doctors as the health professionals with a negative influence on successful breast-feeding. No further subdivisions of items were possible by means of the Friedman test at $5 \%$ and $10 \%$ significance levels.

Applying Fisher's exact test (two-tail), a significantly higher proportion of respondents with further training in breast-feeding mentioned improper management of breast-feeding in hospital as an obstacle to successful lactation $(p=0,016)$. Proportionally more respondents who completed their questionnaires in Afrikaans tended to mention this obstacle as well ( $p=0,098)$. Respondents trained at Afrikaans institutions also tended to mention wrong or conflicting advice, or lack of knowledge proportionally more as obstacle $(p=0,067)$.

With regard to society as obstacle, 19 respondents identified four items: lack of support and encouragement from family and friends; life-style and social pressures; lack of baby care facilities at shopping centres; and the availability of alternative feeding (see Table 4). Applying the Friedman test at a 5\% significance level (Phase A), the availability of alternative feeding $(n=1)$ was significantly less important than lack of support, which had the highest frequency $(n=16)$. Applying the Friedman test to the remaining three significant items (Phase $B$ ), the lack of baby care facilities $(n=2)$ also became significantly separated from the lack of support. Thus the two most important obstacles that remained at a $10 \%$ level of significance were lack of support, and life-style and social pressures.

\section{Motivation for successful breast-feeding}

Successful methods of motivating women to breast-feed were mentioned by 47 respondents and are summarised in Table 5. Applying the Friedman test at $5 \%$ and $10 \%$ significance levels, two significantly important methods of motivation were identified by respondents. They were information and education $(52,5 \%$, $\mathrm{n}=31$ ) and contact with successful breast-feeders $(27,1 \%, n=16)$. Respondents with further training in breast-feeding indicated information and education significantly more than those without further training (Fisher's two-tail test, $\mathrm{p}=0,019$ ).

Other methods mentioned were: support by significant others (e.g. male partner, hospital staff or childbirth educator $(10,2 \%, n=6)$; specific educational methods e.g. videos, literature, group discussions $(8,5 \%, n=5)$; individual consultations $(5,1 \%, n=3)$; and nipple preparation $(1,7 \%, \mathrm{n}=1)$. Proportionally more respondents completing the questionnaire in Afrikaans tended to identify support of significant others as a method of motivation (Fisher's two-tail test, $\mathrm{p}=0,092$ ).

\section{DISCUSSION}

The results of this questionnaire reflect the feedback from clients of obstetric physiotherapists. The majority of respondents indicated that their clients were from the middle and upper income groups and therefore the results do not necessarily reflect the perceptions of health workers dealing with other groups of South African mothers.

The results should also be interpreted in the light of possible shortcomings associated with open-ended questions. Some respondents tended to give more detailed answers; others were more proficient at expressing themselves clearly. Respondents may also have marked more or fewer items if the questionnaire had been in a closed format. The reliability of these results could have been enhanced by applying a structured questionnaire to a similar control group.

Although the study was conducted among obstetric physiotherapists, the results have important implications for midwives and community nurses. Nurses are the health professionals who have contact most regularly with mothers of small babies and can, therefore, make an important contribution in eliminating obstacles to successful breast-feeding and in supporting and motivating mothers to initiate breast-feeding or to continue when problems arise.

\section{Obstacles to successful breast-feeding}

Maternal obstacles to successful breast-feeding were identified by 47 of the respondents, compared to 27 respondents mentioning health professionals as obstacle and 19 mentioning society as obstacle. The prominence respondents gave to maternal obstacles may be an indication that mothers need more motivation and knowledge and that more attention should be given to appropriate educational strategies and the 'marketing' of breast-feeding. It may also indicate that obstetric physiotherapists, due to the nature of their work, focus more on the problems of their clients (mothers) than on other problems.

The maternal obstacles identified by respondents can be broadly classified according to three main causes of these problems, viz. psychological factors, physiological causes and other practical circumstances (see Table 6). The obstacles most frequently mentioned relate to psychological causes, which may be partly overcome by appropriate educational programmes and individual counselling. These causes are, however, also a reflection of the obstacles society poses to successful breast-feeding. Black et al. (1990:258) claim that "maternal attitudes toward breast feeding must be consistent with the individual, family, and social system goals if breast feeding is to be attempted."

If the psychological obstacles can be overcome, many of the physiological and practical obstacles listed by respondents may also be overcome in adequately motivated mothers through education and practical assistance and support by care-givers.

Nearly half $(47 \%)$ of the respondents identified health professionals and health services as obstacles to successful breast-feeding. Doctors were mentioned specifically by nearly one fifth of all respondents $(18,6 \%)$, which indicates a need for continuing education to update their knowledge and to change attitudes. For example, Maasdorp and Loening (1989:397) found that $80 \%$ of doctors and nurses participating in a survey in Natal/kwaZulu gave unhelpful and confusing answers to the question 'What advice would you give to a mother of a two-week old baby who states that she has insufficient breast-milk to satisfy her baby?' In this regard, Naylor (1984:47) states that professional training in clinical evaluation and breast-feeding management is still rare. She continues: "Many perinatal health care providers enter practice unprepared to assist the nursing mothers and often give advice and carry out procedures leading to breast-feeding problems and failures." Delport et al. (1988:396) found that none of the mothers interviewed in their study at a private South African maternity hospital perceived that they had received any factual information on breast-feeding from their medical practitioner during pregnancy. In this regard, Black et al. (1990:259) feel that physicians should be more aggressive in initiating discussions on feeding methods.

Other areas in which nurses and maternity facilities could investigate their own practices are those concerned with the improvement of hospital practices and providing better support for breast-feeding mothers. Delport et al. (1988:396-7) found the following potentially detrimental practices in their study:unnecessary separation of mother and infant after birth, delay in the initiation of breast-feeding, unnecessary pre-lacteal and complementary feeds, and routine test-weighing. The improvement of hospital practice is also high on the list of priorities in health circles world-wide. In 1989 the World Health Organization and UNICEF issued "Ten Steps to Successful Breast-feeding". The Health Matters Committee, as South African 
statutory body, adopted a slightly modified version of this statement as national breast-feeding policy for South Africa in 1990 (see Appendix). The "Ten Steps" also form the basis of the Baby-Friendly Hospital Initiative of UNICEF and other organisations. "Baby-Friendly hospitals" was the theme of the first World Breast-feeding Day on August 1,1992 and is also the theme of the sixth South African National Breast-feeding Week in March 1993. Midwives and community health nurses could make the implementation of the "Ten Steps" one of the objectives for improved nursing care. A suggested project for future research is an evaluation of how many hospitals have implemented what number of the "Ten Steps" by the year 1995 a target set by the Innocenti Declaration of 1990.

The question of breast-feeding support is closely linked with the obstacles in society which may influence breast-feeding success. These are probably the most difficult to overcome, because it requires the re-orientation of the attitudes and beliefs of a whole group of people. Van Esterik (1989:69) contends that "breast-feeding requires structural changes in society to improve the position and condition of women" in order that women can have more control over their lives. A position statement of the Canadian Dietetic Association (1989:211) encourages the development and strengthening of educational and social support systems to encourage, facilitate and protect breast-feeding. The most important people needing re-orientation are those identified by the mother as the significant others. Ten percent of respondents also indicated support by significant others as a method of motivation for a mother to breast-feed. Black et al. (1990:259) recommend that prenatal instruction be combined with postpartum breast-feeding support, with the aim of increasing the incidence and duration of breast-feeding.

Life-styles and social pressures, the second obstacle in society mentioned by respondents, illustrates the need for information to reach mothers about how to adapt breast-feeding practices to these life-styles, or how to change life-styles in order to accommodate breast-feeding. One example, which has been classified under maternal obstacles, is maternal employment. For instance nurses can assist a mother by providing information on available options to combine breast-feeding and work (Bergh 1991).

Although only mentioned by two respondents, baby care facilities in public places have received much attention lately. As a result of the breast-feeding week activities, some shopping centres and pharmacies, have started to provide such facilities (SA Consumer 1990:29). Some respondents to a questionnaire evaluating the activities of the breast-feeding weeks also indicated that they were instrumental in establishing a breast-feeding facility or baby room (unpublished data). Nurses could help in increasing these facilities by investigating whether adequate facilities exist and by joining forces with the general public in lobbying for the establishment of such facilities.

The availability of alternative methods of feeding was mentioned by one respondent This again brings to attention the responsibilities of the nurse with regard to implementing the principles of the South African Code of Ethics for the Marketing of Breast-milk Substitutes (NHPD 1986). These responsibilities have been clarified elsewhere (Bergh \& Wagstaff 1987; Ransome 1988).

\section{Motivation for successful breast-feeding}

More than half of all respondents (53\%) considered information and education as an important method of motivation for breast-feeding. The fact that $27 \%$ of all respondents mentioned contact with other mothers who have successfully breast-fed shows the important influence of the breast-feeding mother to teach the breast-feeding section of her antenatal classes. Involving counsellors or members of breast-feeding organisations in breast-feeding education may be a way of helping the mother to come into contact with other mothers with babies. The last recommendation of the national breast-feeding policy recommends that health workers should foster the establishment of support groups and should refer mothers to them.

The support by significant others as a method of motivation has been mentioned already. Specific educational methods, mentioned by $9 \%$ of respondents, is a reminder that teaching alone does not guarantee motivation for breast-feeding, but that childbirth educators need training in specific methods which are relevant and which would appeal to their audiences. Five percent of respondents mentioned individual consultations as a method of motivation. For this, training in counselling skills is a necessity. Nipple preparation was mentioned by one respondent. Although nipple preparation is nowadays not considered an essential for breast-feeding any more, some authors are of the opinion that it may help some mothers to "tune in" to breast-feeding at a psychological level (Lawrence 1989:183).

\section{CONCLUSION}

Most nurses probably hear about inadequate health education programmes regularly. Identifying obstacles and methods of motivation with the help of the public and other health professionals may help to improve educational efforts. This may be particularly helpful where data are not readily available in the professional literature or where local circumstances require a different approach. Where necessary the Friedman test may be a statistical method to consider for determining priorities for addressing obstacles to successful breast-feeding and methods of motivation. It may also be a procedure to consider in determing the statistically significant ante- and postnatal concerns of mothers to be addressed in childbirth education programmes.

\section{ACKNOWLEDGEMENTS}

We would like to thank the following persons and institutions: the Obstetric Association of the SA Society for Physiotherapy for their kind co-operation and their permission to publish the results; Margie Pretorius of the Obstetric Association and the Sub-directorate: Nutrition, Department of National Health and Population Development for logistical assistance; Jackie Grimbeek of the Department of Statistics, University of Pretoria, for the statistical analyses; Denise Holton of the Bureau for Computer Services, University of Pretoria, for the computer analyses.

The financial assistance of the Institute for Research Development towards this research is hereby acknowledged. Opinions expressed in this publication and conclusions arrived at, are those of the authors and are not necessarily to be attributed to the Institute for Research Development.

\section{REFERENCES}

Bergh, A-M. (1987). The role of a nongovernmental organization in breast-feeding education. Journal of Nutrition Education, 19(3), 117-124.

Bergh, A-M (1991). Breast-feeding options for the working mother. Nursing RSA, $6(2), 37-40$.

Bergh, A-M., Wagstaff, L.A. (1987. The SA Code of Ethics for the Marketing of Breast-milk Substitutes. Nursing RSA, 2(9), 7-9.

Black, R.F., Blair, J.P., Jones, V.N., Du Rant, R.H. (1990). Infant feeding decisions among pregnant women from a WIC population in Georgia. Journal of the American Dietetic Association, 90(2), 255-259.

Canadian Dietetic Association. (1989) Promoting breast-feeding: the role of the dietician/nutritionist. Journal of the Canadian Dietetic Association, 50(4), 211 214.

Delport, S., Bergh, A-M., Hay, I.T. (1988). Breast-feeding practices in a private maternity hospital. South African Medical Journal, 74, 396-399.

Lawrence, R.A. (1989). Breast-feeding: a guide for the medical profession. 3rd edition. St. Louis: CV Mosby Co. 
Maasdorp, J., Loening, W.E.K. (1989). Are breast-feeding problems iatrogenic? South African Medical Journal, 76397.

Naylor, A.J. (1984). The San Diego Lactation Program: a teaching hospital-bases resource to promote breast-feeding in Report on the Surgeon General's Workshop on Breast-feeding and Lactation. Rockville: US Department of Health and Human Services.

NHPD (Department of National Health and Population Development). (1986). The South African Code of Ethics for the Marketing of Breast-milk Substitutes. Pretoria: Government Printer.

Ransome, O.J. (1988). The SA Code of Ethics for the Marketing of Breast-milk Substitutes. South African Medical Journal, 74375.

SA Consumer. (1990). Breast-feeding is like driving a car. SA Consumer, 2nd quarter 28-29.

Van Esterik, P. (1989). Beyond the breast-bottle controversy. New Brunswick, New Jersey: Rutgers University Press.
TABLE 1 DEMOGRAPHIC PARTICULARS OF RESPONDENTS

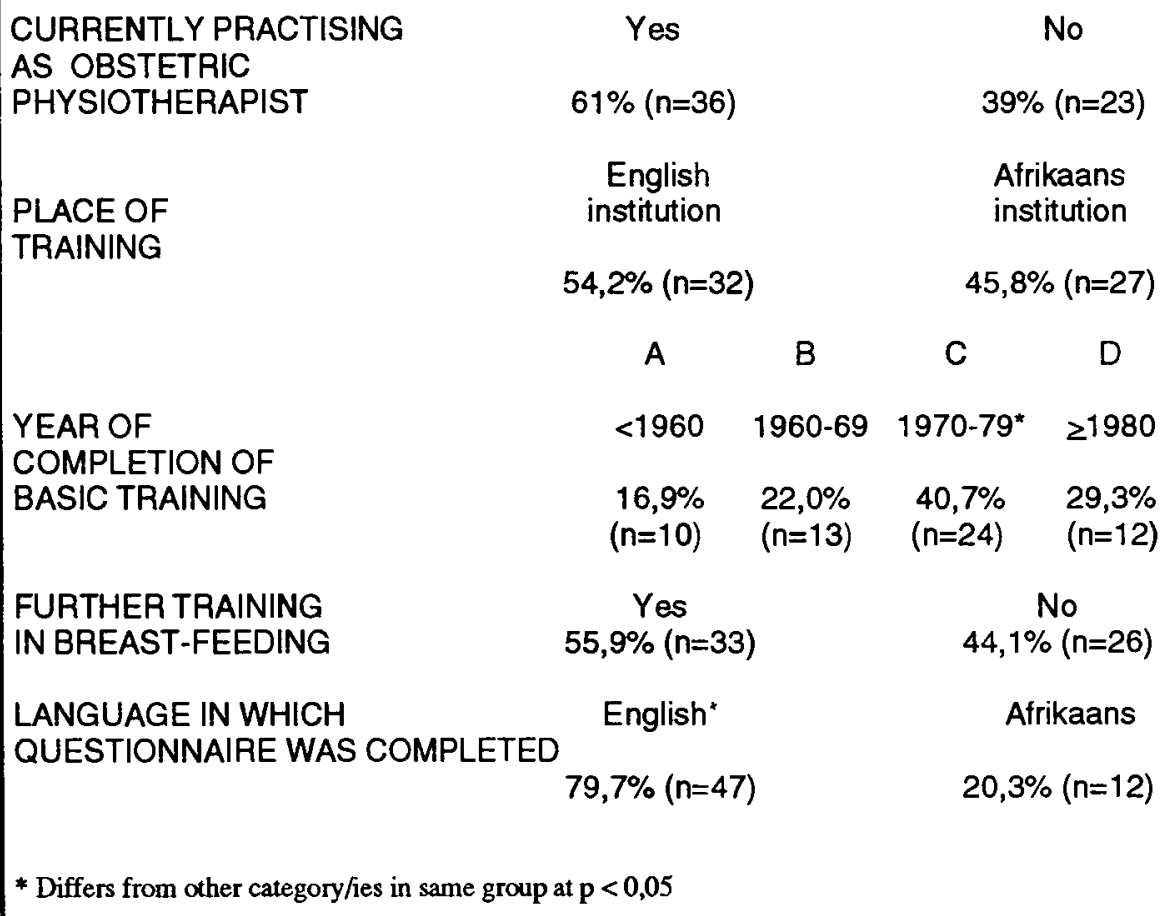

TABLE 2 MATERNAL OBSTACLES TO SUCCESSFUL BREAST-FEEDING $(n=43)$

Insufficient motivation/perseverance, negative attitudes

$\begin{array}{cc}\begin{array}{c}\text { \% of total } \\ (\mathbf{n}=59)\end{array} & \mathbf{n} \\ 25,2 & 15 \\ 23,7 & 14 \\ 13,6 & 8 \\ 13,6 & 8 \\ 13,6 & 8 \\ 5,1 & 3 \\ 5,1 & 3 \\ 3,4 & 2 \\ 1,7 & 1 \\ 1,7 & 1 \\ 1,7 & 1 \\ 1,7 & 1 \\ 1,7 & 1\end{array}$

TABLE 3 HEALTH PROFESSIONALS AS OBSTACLE TO SUCCESSFUL BREAST-FEEDING ( $n=27)$

Anxiety, embarrassment, lack of confidence

Employment, returning to work too soon

Fatigue, tension, stress, exhaustion

Difficulty learning the ant

Nipple pain

Insufficient milk, problems establishing lactation

Untreated breast engorgement

Maternal disease

Presence of siblings

Breast reduction

Lack of time

$\begin{array}{cc}\begin{array}{c}\text { \% of Total } \\ (\mathbf{n}=59)\end{array} & \mathbf{n} \\ 20,3 & 12 \\ 18,6 & 11 \\ 15,1 & 9 \\ 5,1 & 3 \\ 5,1 & 3 \\ 1,7 & 1\end{array}$


OBSTACLE

Lack of support and encouragement from family and friends

Life-style and

social pressures

Lack of baby care facilities

at shopping centres

Availability of

alternative feeding

\section{PERCENTAGE OF TOTAL OF RESPONDENTS}

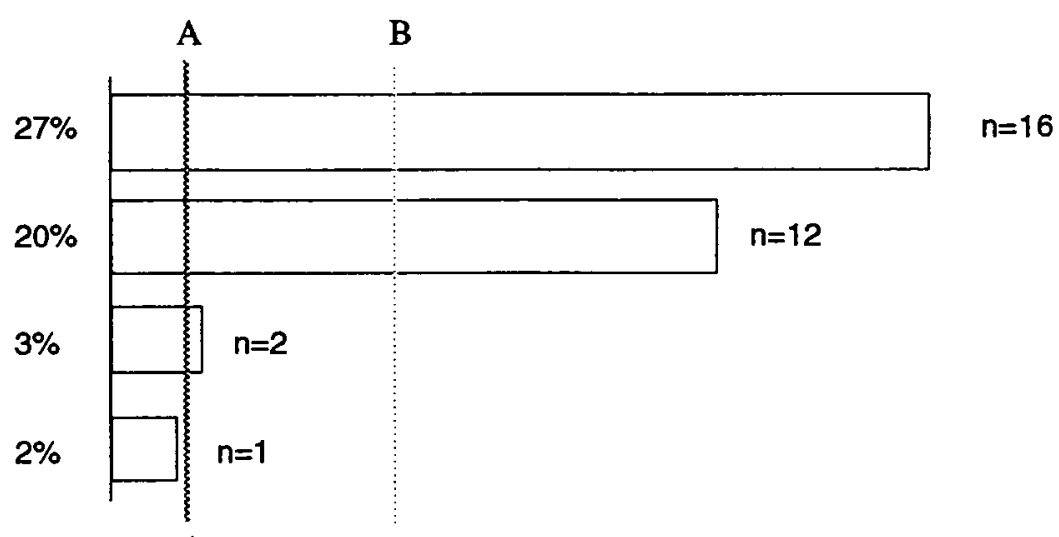

A Division between important and less important obstacles at a $5 \%$ level of significance

B Division between important and less important obstacles at $10 \%$ of significance

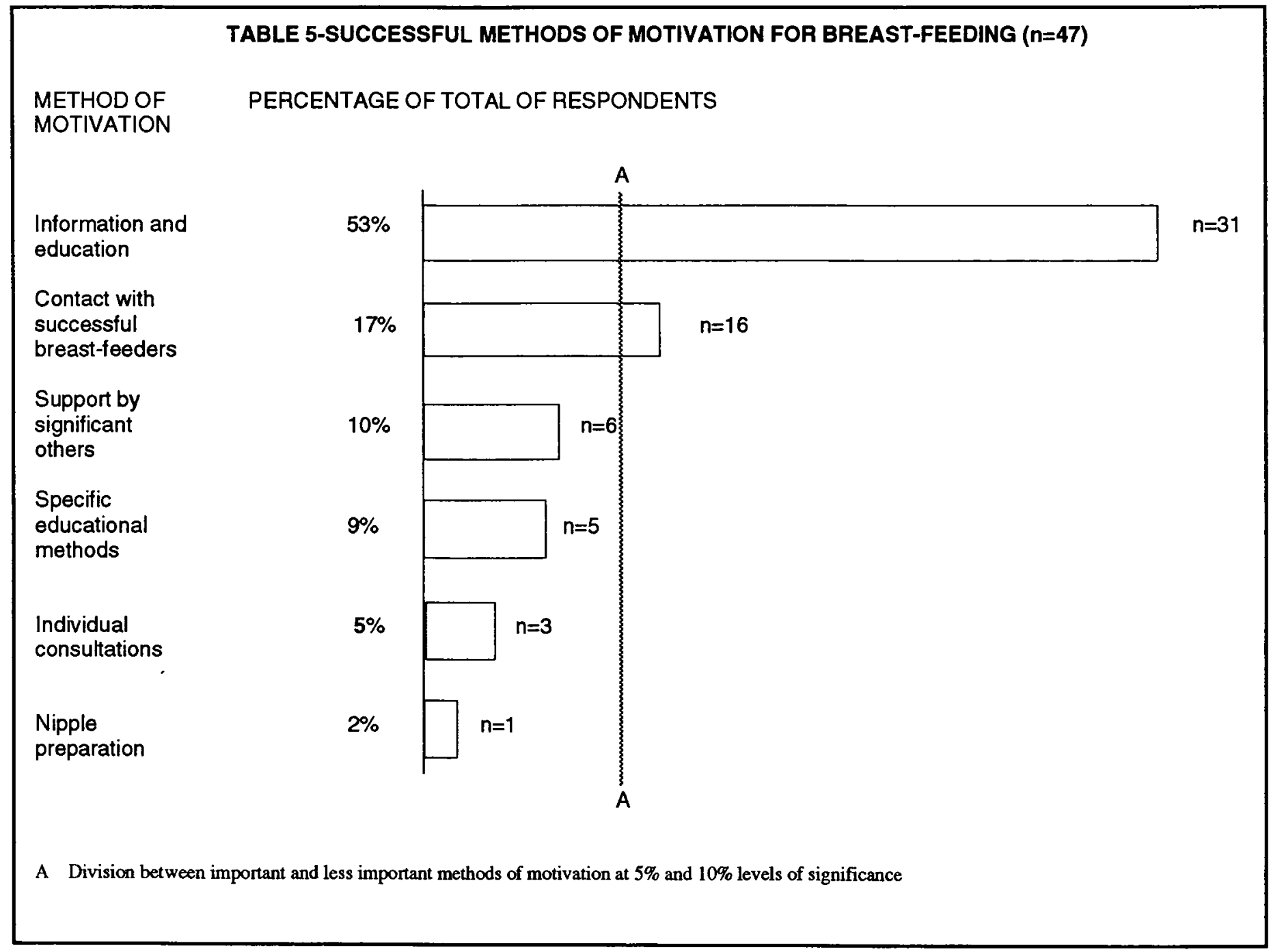




\begin{tabular}{|c|c|}
\hline \multicolumn{2}{|c|}{ TABLE 6 CAUSES OF MATERNAL OBSTACLES TO BREAST-FEEDING } \\
\hline CAUSE & OBSTACLE \\
\hline \multirow{4}{*}{$\begin{array}{l}\text { PSYCHOLOGICAL } \\
\text { FACTORS }\end{array}$} & Insufficient motivation/perserverance negative attitudes $(n=15)$ \\
\hline & $\begin{array}{l}\text { Ignorance, insufficient knowledge, not } \\
\text { well prepared, unenlightened }(n=14)\end{array}$ \\
\hline & Anxiety, embarrassment, lack ofconfidence $(n=8)$ \\
\hline & Fatigue, tension, stress, exhaustion $(n=8)$ \\
\hline \multirow{6}{*}{$\begin{array}{l}\text { PHYSIOLOGICAL } \\
\text { OBSTACLES }\end{array}$} & Difficulty learning the art $(n=3)$ \\
\hline & Nipple pain $(n=3)$ \\
\hline & $\begin{array}{l}\text { Insufticient milk, problems } \\
\text { establishing lactation }(n=2)\end{array}$ \\
\hline & Untreated breast engorgement $(n=1)$ \\
\hline & Maternal disease $(n=1)$ \\
\hline & Breast reduction $(n=1)$ \\
\hline \multirow{3}{*}{$\begin{array}{l}\text { PRACTICAL } \\
\text { CIRCUMSTANCES }\end{array}$} & Employment, returning to work too soon $(n=8)$ \\
\hline & Presence of siblings $(n=1)$ \\
\hline & Lack of time $(n=1)$ \\
\hline
\end{tabular}

\section{APPENDIX : \\ NATIONAL BREAST-FEEDING POLICY}

Every facility providing maternity services and care for newborn infants shoud:-

1. Have a written breast-feeding policy that is routinely communicated to all health care staff.

2. Train all health care staff in skills necessary to implement this policy.

3. Inform all pregnant wormen about the benefits and management of breast-feeding.

4. Help mothers initiate breast-feeding within half an hour of birth.

5. Show mothers how to breast-feed, and how to maintain lactation even if they should be separated lirom their infants.

6. Give newbom infants nomilk feeds or water other than breast-milk, unless indicated for a medical reason.

7. Allow mothers and infants to remain together 24 hours a day from birth.

8. Encourage natural breast-feeding frequently and on demand.

9. Do not give, or encourage, the use of artificial teats or dummies to breast-fed infants. Do not encourage the use of nipple shields either.

10. Promote the establishment of breast-feeding support groups and refer mothers to these on discharge from the hospital or clinic. 